Photographic observations of asteroids.

\begin{tabular}{c|c|c|c}
\hline Asteroid & $\alpha$ I907.0 & $\delta$ I907.0 & Mg. \\
\hline
\end{tabular}

Plate 340. I 907 Febr. 4. $15^{\mathrm{h}} 10^{\mathrm{m}}-18^{\mathrm{h}} 10^{\mathrm{m}} \mathrm{Gr}$. ( 165 ) Loreley (402) Chloë (2 I) Lutetia 1907 XR (new) (r 29) Antigone I $907 \mathrm{XL}$ (30) Urania

\begin{tabular}{|rr|rr|r}
$8^{\mathrm{h}} 4^{2} \mathrm{~m}^{\mathrm{m}} \cdot 9$ & $+\mathrm{I} 6^{\circ}$ & $4^{\prime}$ & $12^{\mathrm{m}} \cdot 5$ \\
8 & 44.2 & +18 & 53 & 10.5 \\
8 & 48.2 & $+2 \mathrm{I}$ & 37 & 12.0 \\
8 & 57.1 & +16 & 53 & 15.0 \\
8 & 59.8 & +15 & 55 & 11.5 \\
9 & 6.3 & +18 & 54 & 13.5 \\
9 & 9.4 & +15 & 56 & 11.7
\end{tabular}

\begin{tabular}{|c|c|c|c|}
\hline Asteroid & $\alpha 1907.0$ & $\delta 1907.0$ & Mg. \\
\hline & \multicolumn{3}{|c|}{ Febr. 7. $\quad 16^{\mathrm{h}} 45^{\mathrm{m}}-19^{\mathrm{h}} 45^{\mathrm{m}}$ Gr } \\
\hline$(165) \mathrm{I}$ & $8^{\mathrm{h}} 40^{\mathrm{m}} \cdot 4$ & $+16^{\circ} 5^{\prime}$ & $11 \mathrm{~m}_{4}$ \\
\hline (402) Chloë & 841.5 & +1922 & 10.5 \\
\hline (2 I) Lutetia & 844.9 & +2150 & 10.9 \\
\hline I $907 \mathrm{XR}$ & 854.6 & +175 & I 5.0 \\
\hline (1 29) Antigone & 857.2 & +1617 & I I.3 \\
\hline I $907 \mathrm{XL}$ & $9 \quad 3.6$ & +1910 & I 3.5 \\
\hline$(3 \circ$ & 96.2 & +16 & 11.7 \\
\hline$(569)$ Misa & 99.0 & +1555 & I 3.0 \\
\hline
\end{tabular}

Percival Lowell.

Lowell Observatory, Flagstaff, Ariz., I 907 Febr. 21.

Photographische Aufnahmen von kleinen Planeten.

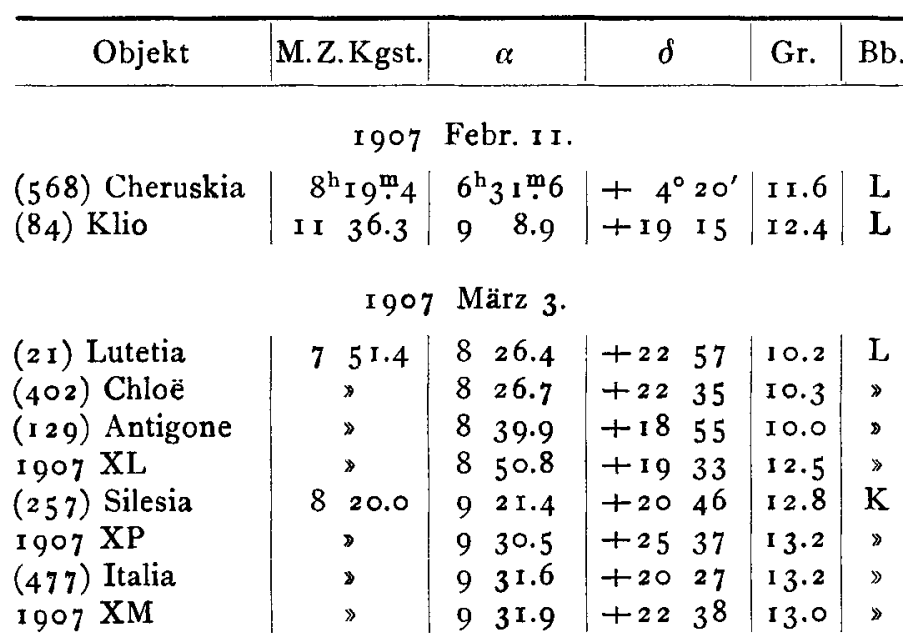

Tägl. Beweg: (2 I) $-0^{\mathrm{m}} 6+\mathrm{I}^{\prime}$, (129) $-0^{\mathrm{m}} \cdot 7+6^{\prime}$, $\mathrm{XL}-0^{\mathrm{m}} 6 \circ^{\prime}, \mathrm{XP}-0^{\mathrm{m}} 8+2^{\prime}, \mathrm{XM}-0^{\mathrm{m}} \cdot 5-\mathrm{I}^{\prime}$.

$$
\mathrm{K}=A . \text { Kopff, }
$$

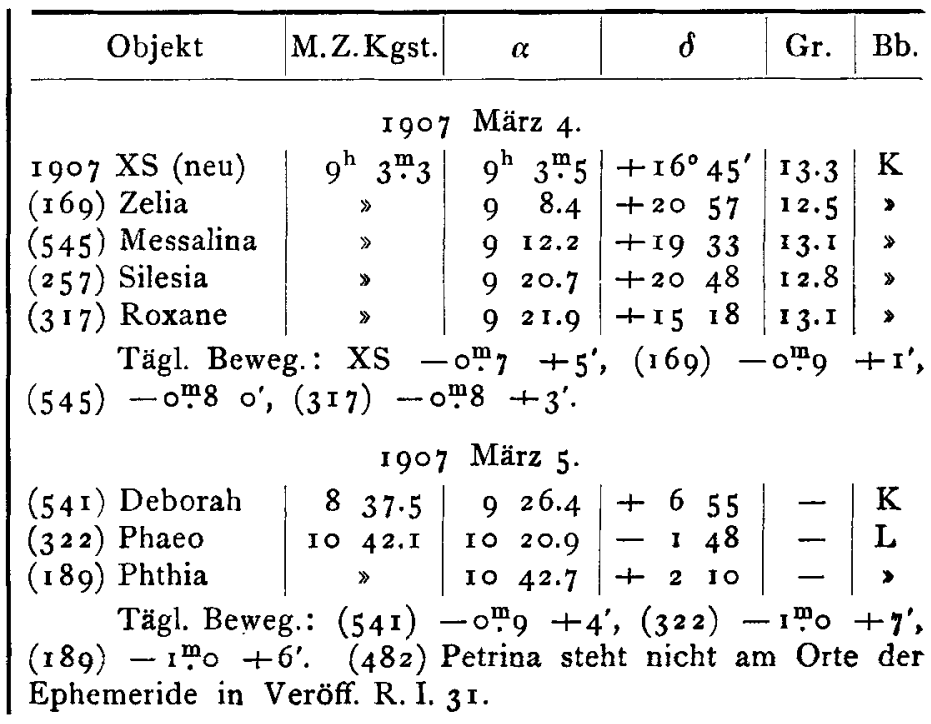

M. Wolf.

$\mathrm{L}=K$. Lohnert.

Astrophys. Institut Königstuhl-Heidelberg, r 907 März 7 .

\title{
Entdeckung eines neuen Kometen 1907 a.
}

Am ıo. März nachmittags ging folgendes Telegramm von der Sternwarte Nizza ein:

¿Comète Giacobini I I magnitude 9 mars $10^{\text {h }}$ I $0^{m_{9}}$ temps moyen Nice AR. app. $=106^{\circ} 7^{\prime} 5^{\prime \prime}$ DP. app.

$=108^{\circ} 21^{\prime} 17^{\prime \prime}$ mouv. diurne $-47^{\prime}-57^{\prime}$ Bassot. $\kappa$

Wegen einer notwendigen Rückfrage konnte die Weiterbeförderung des Telegramms erst in der Nacht vom 10. auf den I I. März erfolgen.

Am 11. März ging noch folgende Beobachtung aus Nizza telegraphisch ein:

Io mars $10^{\mathrm{h}} 26^{\mathrm{m}} \circ$ O Nice $a$ app. $=$ I05 $^{\circ} 23^{\prime} 1^{\prime \prime} \delta$ app. $=-\mathrm{I}^{\circ} 23^{\prime} 23^{\prime \prime}$ Gr. I1 ${ }^{\mathrm{m}}$ Bassot. Kr.

(481) Emita. Korrektion der Ephemeride (Veröff. R. I. 3I): I907 März 5 + Ios -o:7. E. Przybyllok. 